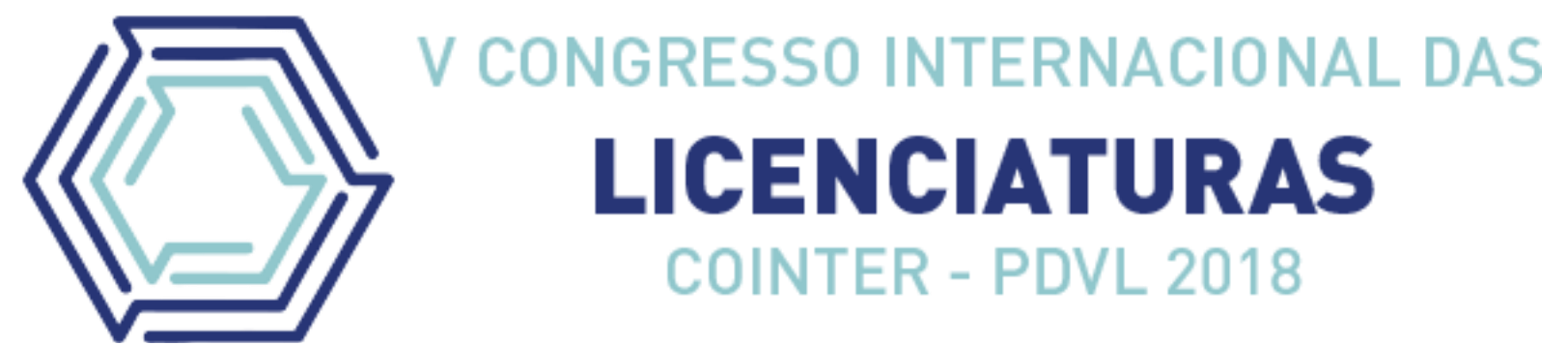

\title{
VIVÊNCIA DA REALIDADE ESCOLAR E PLANEJAMENTO NO ENSINO DE QUÍMICA
}

\section{EXPERIENCE OF SCHOOL REALITY AND PLANNING IN TEACHING CHEMISTRY}

\author{
Apresentação: Relato de Experiência \\ Rosiane Antonia Cavalcanti ${ }^{1}$ - Instituto Federal de Pernambuco- \\ rosiane.cavalcanti2016@gmail.com; \\ Maria Grasielly Felix Brandão² - Instituto Federal de Pernambuco- \\ grasiellybrandao2000@gmail.com
}

Orientador: Cláudio Henrique Alves Perdigão- Instituto Federal de Pernambucoclaudio.perdigao@vitoria.ifpe.edu.br

DOI: https://doi.org/10.31692/2358-9728.VCOINTERPDVL.2018.00327

\section{Introdução}

A experiência de observação se constituiu em um importante momento para o nosso desenvolvimento profissional, sobretudo porque nos proporciona uma primeira vivência direta de uma sala de aula com o olhar de um futuro professor. O cenário deste particular momento em que tivemos a oportunidade de observar os pontos positivos e negativos de um possível futuro espaço de atuação foi em uma escola municipal da Zona da Mata de Pernambuco. Conforme está posto na ementa da disciplina de Prática I, o relatório de observação orienta-se para uma "Vivência da realidade escolar e planejamento no Ensino de Química" e, de conformidade com a ementa o professor estabeleceu como principal objetivo do curso: Investigar a realidade da sala de aula, no contexto da escola, particularmente o processo de ensino e aprendizagem de química no ensino fundamental e planejar futuras intervenções nas salas de aula. Serão apresentados alguns fragmentos de respostas à perguntas feitas ao professor. Naturalmente que o nosso novo olhar, mais próximo de um olhar de professor, não poderia ser nem despojado nem descomprometido, mas orientado para objetivos claros que se

Rosiane A. Cavalcanti; Instituto Federal de Pernambuco; rosiane.cavalcanti2016@gmail.com Maria Grasielly F. Brandão; Instituto Federal de Pernambuco; grasiellybrandao2000@gmail.com Cláudio Henrique A. Perdigão; Instituto Federal de Pernambuco; claudio.perdigao@vitoria.ifpe.edu.br 
traduzem naquilo que Freire (1996) chama de curiosidade epistemológica. Nesse sentido, a primeira parte do curso foi dedicada ao planejamento da futura investigação da realidade escolar.

Além de observar e auxiliar o andamento de algumas aulas de Química a nível fundamental, através do referido componente curricular, teve-se a oportunidade de observar alguns aspectos que consideramos importantes para o processo de formação de um futuro educador de Química.

\section{Relato de Experiência}

Com relação ao conhecimento do ambiente escolar, os momentos iniciais na escola foram de observação da análise do espaço, estrutura física e organizacional. Para isso, primeiramente, buscamos o conhecimento da situação da escola em termos de estrutura física, socio-histórica e também da formação dos professores. A obtenção dos dados foi feita a partir de uma entrevista semiestruturada que, de acordo com Paulo Freire "Ensinar não é transferir conhecimento, mas criar as possibilidades para a sua própria produção ou a sua construção".

O contato foi apenas através de observações, em que procurou-se identificar alguns pontos relativos à realidade da sala de aula, tais como: domínio de conteúdo do professor, participação dos alunos e recursos utilizados durante a aula. Quanto à entrevista semiestruturada feita na escola Municipal, foram coletados alguns dados referentes à formação do entrevistado, onde o Professor informa que:

\section{“Licenciado em Química há dois anos".}

Perguntou-se a diretora quais as condições físicas da escola e obteve-se a seguinte resposta:

\footnotetext{
"Como vocês podem conferir nossa escola passou por uma reforma a pouco tempo, porém ainda há um déficit. "Precisamos de um laboratório e que esta nos futuros planos de uma possivel nova reforma para a construção de novas salas e de um possível laboratório."
}

De fato analisou-se a comprovação da reforma, e que ainda existe alguns aspectos que precisa de uma resolução mais abstrata. Quanto à entrevista do Professor, podendo-se destacar 
algumas falas que são relevantes no presente trabalho. Indaga-se que identificava-se com a sua profissão e a partir do que foi dito:

\footnotetext{
"Que sente um prazer imenso em ensinar Química, que sempre se identificou com a matéria e que não se arrepende de ter escolhido essa profissão, pois faz tudo com muito amor. ",
}

De acordo com o perfil do professor pode-se afirmar que o conhecimento e o amor pela profissão soma pontos positivos que o ajuda a ser um profissional cada vez mais qualificado e com boas experiências. Segundo Albert Einstein:

\footnotetext{
"Não basta ensinar ao homem uma especialidade, porque se tornará assim uma máquina utilizável e não uma personalidade. "É necessário que adquira um sentimento, senso prático daquilo que vale a pena ser empreendido, daquilo que é belo, do que é moralmente correto."
}

A educação é mais do que um processo de transmissão de conhecimento. É um processo formador amplo, capaz de construir personalidades, de edificar cidadãos conscientes, reflexivos, ativos e críticos. Todos os envolvidos no processo educacional devem entender que sua posição, suas atitudes, a sua forma de relacionar-se com os educandos, relaciona-se a uma forma de educar e formar alguém, a influência disso é que diferencia uma boa formação de uma simples preparação de conteúdos didáticos. Deve-se pensar na educação como formação humana, e não simplesmente como preparação profissional.

No primeiro encontro de observação, o Professor havia proposto aos alunos uma atividade sobre as Transformações da Matéria. Essa atividade correspondia a um texto com o seguinte título: "Fenômenos Físicos". Cada aluno teria que ter lido o seu respectivo texto em casa o qual havia sido entregue com antecipação pelo professor, e na aula seguinte prosseguir com um debate sobre o que havia entendido sobre o mesmo. Dessa forma, eles teriam que expor suas ideias, procurando interagir com a turma, expressando os seus pontos de vistas em relação ao texto. Pudemos perceber que os objetivos almejados pelo professor foram alcançados nessa aula, pois percebemos que houve a participação e interação entre os alunos e o professor de uma forma saudável.

Percebe-se que a relação entre professor e aluno é consideravelmente boa, com uma participação de quase todos os alunos na realização das atividades, contudo temos que relatar também que nem sempre todos os alunos participavam de todas as atividades, havia aqueles que tinham certa resistência na realização das atividades. 
Por se tratar de uma escola do município, a avaliação da instituição ocorre de forma diferenciada da que estamos acostumados a vivenciar. Trata-se de uma avaliação sócio afetiva na qual se observa sempre a posição dos alunos para com as atividades; além dos aspectos culturais e cognitivos. As avaliações eram obtidas através de resumos, relatórios, seminários, exercícios e etc. Portanto não são avaliados por notas e sim por progresso, dependendo do seu desenvolvimento acadêmico.

\section{Considerações}

Relata-se que este trabalho proporciona uma oportunidade de conhecer a realidade que encontra-se em sala de aula, podendo-se assim afirmar que essa experiência trará para a formação acadêmica perspectivas otimistas e obteve-se informações que auxiliaram numa reflexão mais intensa em relação ao estado da educação daquele lugar em específico. Teve-se também a oportunidade de analisar algumas aulas de Química para o ensino fundamental da escola.

Participar da rotina escolar foi um gesto fundamental para o aprimoramento pedagógico e consolidação das teorias apreendidas durante a graduação em Licenciatura em Química, e sem falar que estar próximo do trabalho docente permite a desconstrução de determinados mitos que alimentamos durante a passagem pela universidade, o que chega até os estudantes de graduação é uma visão negativa da escola e do trabalho do professor.

Os relatos das aulas apresentados aqui é uma tentativa de demostrar que a docência não é mais do que uma atividade produtiva, se caracterizando como um trabalho como qualquer outro na sociedade, precisando de boas condições para a execução do trabalho e uma remuneração digna que respeite a necessidades da reprodução social da pessoa. Os professores e professoras da rede pública desempenham um papel fundamental na formação de pessoas, isso não dá a eles e elas o direito de ensinar por "amor", a docência é um trabalho sério que deve ser respeitado em quanto tal, deve ser dada atenção para as melhoras da execução do trabalho dos docentes nas escolas visando a melhora da qualidade do ensino.

\section{Referências}

EINSTEIN.Albert-Pensador-Disponivel em $<$ Estimular a curiosidade crítica é tarefa fundamental da educação $>$. Acesso em:10 Out. 2018. 
FONSECA.André Azevedo. Disponivel em< ://www.huffpostbrasil.com/andre-azevedo-dafonseca/estimular-a-curiosidade-critica-e-tarefa-fundamental-da-educacao_a_21689985/>. 